OPEN ACCESS

Edited by:

Xinghong Yang,

Shandong Agricultural University,

China

Reviewed by:

Asim Masood,

Aligarh Muslim University, India

Jitender Giri,

National Institute of Plant Genome

Research (NIPGR), India

${ }^{*}$ Correspondence:

Petronia Carillo

petronia.carillo@unicampania.it

Specialty section:

This article was submitted to

Plant Abiotic Stress,

a section of the journal

Frontiers in Plant Science

Received: 10 December 2018

Accepted: 11 February 2019

Published: 07 March 2019

Citation:

Annunziata MG, Ciarmiello LF

Woodrow P, Dell'Aversana E and Carillo P (2019) Spatial and Temporal

Profile of Glycine Betaine

Accumulation in Plants Under Abiotic

Stresses. Front. Plant Sci. 10:230.

doi: $10.3389 /$ fpls.2019.00230

\section{Spatial and Temporal Profile of Glycine Betaine Accumulation in Plants Under Abiotic Stresses}

\author{
Maria Grazia Annunziata', Loredana Filomena Ciarmiello², Pasqualina Woodrow², \\ Emilia Dell'Aversana ${ }^{2}$ and Petronia Carillo ${ }^{2 *}$
}

${ }^{1}$ Department of Metabolic Networks, Max Planck Institute of Molecular Plant Physiology, Potsdam, Germany, ${ }^{2}$ Dipartimento di Scienze e Tecnologie Ambientali, Biologiche e Farmaceutiche, Università degli Studi della Campania "Luigi Vanvitelli", Caserta, Italy

Several halophytes and a few crop plants, including Poaceae, synthesize and accumulate glycine betaine (GB) in response to environmental constraints. GB plays an important role in osmoregulation, in fact, it is one of the main nitrogen-containing compatible osmolytes found in Poaceae. It can interplay with molecules and structures, preserving the activity of macromolecules, maintaining the integrity of membranes against stresses and scavenging ROS. Exogenous GB applications have been proven to induce the expression of genes involved in oxidative stress responses, with a restriction of ROS accumulation and lipid peroxidation in cultured tobacco cells under drought and salinity, and even stabilizing photosynthetic structures under stress. In the plant kingdom, GB is synthesized from choline by a two-step oxidation reaction. The first oxidation is catalyzed by choline monooxygenase $(\mathrm{CMO})$ and the second oxidation is catalyzed by NAD+-dependent betaine aldehyde dehydrogenase. Moreover, in plants, the cytosolic enzyme, named $N$-methyltransferase, catalyzes the conversion of phosphoethanolamine to phosphocholine. However, changes in CMO expression genes under abiotic stresses have been observed. GB accumulation is ontogenetically controlled since it happens in young tissues during prolonged stress, while its degradation is generally not significant in plants. This ability of plants to accumulate high levels of GB in young tissues under abiotic stress, is independent of nitrogen $(N)$ availability and supports the view that plant $\mathrm{N}$ allocation is dictated primarily to supply and protect the growing tissues, even under $\mathrm{N}$ limitation. Indeed, the contribution of GB to osmotic adjustment and ionic and oxidative stress defense in young tissues, is much higher than that in older ones. In this review, the biosynthesis and accumulation of GB in plants, under several abiotic stresses, were analyzed focusing on all possible roles this metabolite can play, particularly in young tissues.

Keywords: glycine betaine (GB), salinity, osmotic adjustment, compatible compound, CMO, ROS

\section{GLYCINE BETAINE METABOLIC PATHWAYS}

Diverse halophytes, but only a few crop plants, including Poaceae, synthetize and accumulate glycine betaine (GB) in response to environmental constrains (Weretilnyk et al., 1989).

In plants, GB synthesis starts from choline, which, in turn, is synthesized through three sequential adenosyl-methionine dependent methylations of phospho-ethanolamine (PE) catalyzed by the cytosolic enzyme phospho-ethanolamine $N$-methyltransferase (PEAMT; EC 2.1.1.103) 
(Nuccio et al., 2000). The PEAMT enzyme has two methyltransferase domains in tandem at the $\mathrm{N}$ and C-terminal domains; the former converting PE into phosphomonomethylethanolamine (P-MME), and the latter methylating P-MME to phospho-dimethylethanolamine (P-DME) and P-DME to phospho-choline (Brendza et al., 2007). The product of PEAMT is phospho-choline (PC) which in different plants can undergo different pathways for the transformation to choline. In spinach, PC is directly dephosphorylated to choline, while in tobacco it is first included in phosphatidyl-choline and then metabolized to choline (McNeil et al., 2001). Subsequently, GB is synthesized by two oxidations on choline, via betaine aldehyde, catalyzed by a ferredoxin-dependent choline monooxygenase (CMO; EC 1.14.15.7), and a NAD ${ }^{+}$-dependent betaine aldehyde dehydrogenase (BADH; EC 1.2.1.8), respectively (Rhodes and Hanson, 1993; Sakamoto and Murata, 2002; Chen and Murata, 2011) (Figure 1A). CMO has a Rieske-type [2Fe-2S] active site, in addition to a transit peptide sequence, and it is usually localized in the chloroplast or other subcellular compartments (Rathinasabapathi et al., 1997). BADH can be either $\mathrm{NAD}^{+}$or $\mathrm{NADP}^{+}$dependent, but in plants it shows higher activity with $\mathrm{NAD}^{+}$(Fitzgerald et al., 2009). It belongs to the superfamily of aldehyde dehydrogenases, and also has a non-specific action on other aldehyde substrates: this also explain its presence in non-GB accumulating plants or in organs of plants that do not contain GB (Rhodes et al., 2002). BADH is induced by abscisic acid (ABA) in cereals, but neither $\mathrm{NaCl}, \mathrm{ABA}$ nor turgor reduction seem to be directly involved in the induction, but rather in an unknown signal coming mainly from roots as well as other plant parts (Takabe et al., 1998).

Chenopodiaceae, such as spinach and sugar beet, have CMO and $\mathrm{BADH}$ enzymes localized in the chloroplast stroma (Fujiwara et al., 2008). In Hordeum vulgare, a peroxisomal NADPHdependent $\mathrm{CMO}$ is involved in the first step of GB synthesis exerting choline oxidation; while $\mathrm{BADH}$ is localized in the cytosol and in the chloroplast (Weigel et al., 1986).

In animals and many bacteria, a membrane-bound choline dehydrogenase $(\mathrm{CHDH}$; EC 1.1.99.1) catalyzes the oxidation of choline to betaine aldehyde; while the enzyme involved in the second step is $\mathrm{BADH}$ again (Figure 1B). In Arthrobacter globiformis and Arthrobacter pascens a soluble choline oxidase (CHO; EC 1.1.3.17), coded by a single gene $\operatorname{codA}$, catalyzes the direct four-electron oxidation of choline to $\mathrm{GB}$, with betaine aldehyde as an intermediate. It contains a covalently linked flavin adenine dinucleotide (FAD), and acts through two hydridetransfer reactions, the two reductions of flavin and the ratelimiting steps (Ikuta et al., 1977; Rozwadowski et al., 1991; Fan and Gadda, 2005) (Figure 1C). This enzyme has become relevant due to its biotechnological applications for the metabolic engineering of economically important plants for osmotic stress resistance (Sakamoto and Murata, 2000), and the production of sensors for the determination of choline and derivatives in biological fluids (Shimomura et al., 2009; Salvi et al., 2014).

Glycine betaine can also undergo a stress-inducible synthesis, since it may be derived from the serine that is synthetized by the (i) non-phosphorylated glycerate pathway, (ii) the phosphorylated phospho-hydroxypyruvate pathway
(Kleczkowski and Givan, 1988; Igamberdiev and Kleczkowski, 2018), or iii) the salt-stress-induced photorespiratory glycolate pathway (Wingler et al., 2000; Carillo et al., 2008). Serine is the precursor of PE via ethanolamine. In plants, the latter is formed directly by the action of a pyridoxal $5^{\prime \prime}$-phosphate-dependent L-serine decarboxylase (SDC) (Rontein et al., 2001); while in plants and animals, but not in fungi, it can indirectly be synthetized through a base exchange between serine and existing PE (Kwon et al., 2012). Thereafter, the phosphorylation of ethanolamine is catalyzed by a choline/ethanolamine kinase (CEK; EC 2.7.1.32).

Salinity, specifically, increases the $C M O$ and $B A D H$ gene expression two- to three-fold and, consequently, the corresponding enzyme levels (Weretilnyk et al., 1989; Weretilnyk and Hanson, 1990; Rhodes et al., 2002).

Xu et al. (2018) identified a CGTCA-motif in the promoter region of Citrullus lanatus $C M O$ and $B A D H$ genes that are responsive to methyl jasmonate (MeJA). When $C$. lanatus cells were activated by MeJA, they synthetized GB even without osmotic stress, and the new cells derived by the activated ones retained a high GB content without previous stress or MeJA activation. This finding suggests that JA signal transduction is involved in GB biosynthesis, which plays a key role in both osmotic stress tolerance and osmotic stress hardening (Xu et al., 2018).

However, the interactive effects of simultaneous salinity and other stresses can decrease the expression of CMO and the relative GB production (Carillo et al., 2011; Woodrow et al., 2017; Ciarmiello et al., 2018). This is particularly relevant because the step catalyzed by CMO is the rate-limiting one in GB biosynthesis (Bhuiyan et al., 2007). Moreover, it is important to underline that GB is not actively metabolized, therefore its concentration depends on the control of its synthesis, transport and dilution by growth (Rhodes and Hanson, 1993; Carillo et al., 2008).

Ciarmiello et al. (2018), showed that a transcript in durum wheat, coding a putative CMO-like enzyme with a different Rieske-type motif that showed similarity with the $\mathrm{CHO}$, was isolated in Ruegeria sp., Pseudomonas fluorescens, and Rhodococcus sp. suggesting a possible alternative pathway for the production of GB in durum wheat similar to that operating the direct oxidation of choline to GB.

\section{GENETICALLY ENGINEERED BIOSYNTHESIS OF GB}

Different genera, and even different species within the same genus, accumulate contrasting amounts of GB, and are therefore classified as accumulators and non-accumulators (Rhodes and Hanson, 1993). Natural accumulators of GB accumulate large amounts of GB only under abiotic stresses (Storey et al., 1977). Homozygous lines for Bet1 (GB accumulators), that are part of near-isogenic maize lines presenting different GB accumulation capacity, showed a 10-20\% higher biomass under salinity than the non-accumulating lines (Saneoka et al., 1995; Munns and Tester, 2008). Therefore, metabolic engineering strategies, aimed at increasing the synthesis and accumulation of GB, have been 


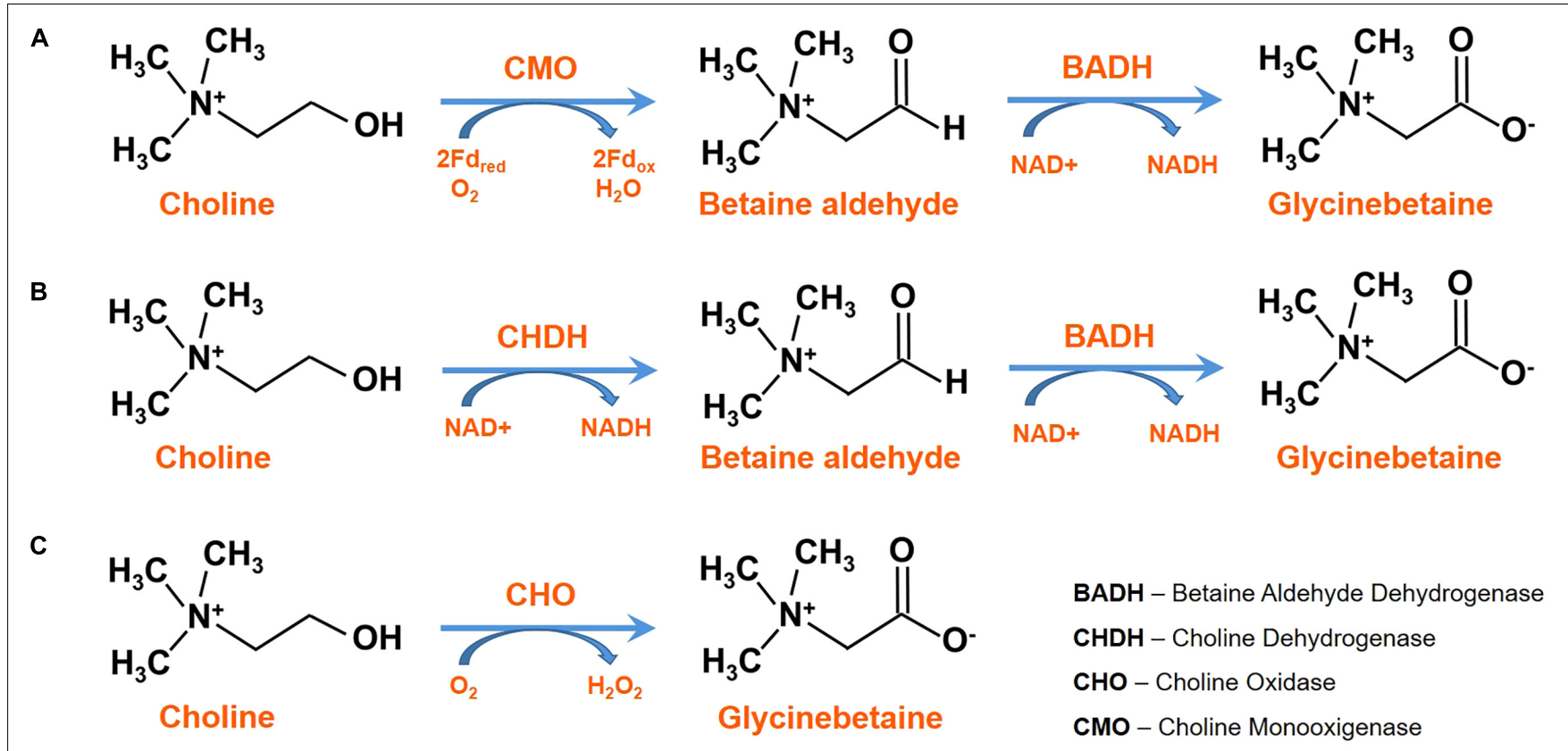

FIGURE 1 | Alternative biosynthetic pathways for glycine betaine (GB) in (A) plants, (B) animals and many bacteria and (C) Arthrobacter globiformis and Arthrobacter pascens.

associated with an amelioration in plant stress tolerance. In particular, important crop species like rice (Oryza sativa), potato (Solanum tuberosum), and tomato (Solanum lycopersicum), which are not able to synthesize and accumulate GB, have been considered as potential targets for metabolic engineering of GB biosynthesis (McCue and Hanson, 1990).

Several genes involved in the GB biosynthetic pathway have been isolated, cloned and used to generate transgenic plants, accumulating GB with an enhanced tolerance to abiotic stress (Wani et al., 2013). The transformations were quite successful for several plant species, improving plant tolerance to salt, drought and extreme temperatures, notwithstanding the very low amounts of GB accumulated by the engineered plants (Nuccio et al., 2000; Sakamoto and Murata, 2002; Chen and Murata, 2008). Among such engineered plants, those transformed with $\operatorname{cod} A$ from $A$. globiformis, encoding the enzyme $\mathrm{CHO}$ that catalyzes the direct oxidation of choline to GB, also showed the accumulation of GB directly in the chloroplasts. In particular, a successful transformation with $\operatorname{cod} A$ was obtained in Arabidopsis thaliana (Hayashi et al., 1997, 1998; Sulpice et al., 2003), Brassica chinensis, Brassica juncea, and Brassica napus (Huang et al., 2000; Prasad et al., 2000; Wang et al., 2010), O. sativa (Sakamoto and Murata, 1998; Mohanty et al., 2002; Kathuria et al., 2009) and even in woody plants such as the Japanese persimmon (Gao et al., 2000) and Eucalyptus globulus (Yu et al., 2009). The plants engineered with $\operatorname{cod} A$ showed an enhanced tolerance to chilling, freezing, salinity, high temperature, and high light in different growth stages, from seed germination to growth, development and reproductive stages (Wani et al., 2013). Likewise, significant success has been achieved by engineering plants with betA, betB or both genes from Escherichia coli encoding $\mathrm{CHDH}$ and BADH, respectively, such as in Gossypium hirsutum (Lv et al., 2007), Medicago sativa (Liu et al., 2011), Nicotiana tabacum (Holmström et al., 2000). codA-transformed rice plants, showed a GB concentration of 5 and $1 \mu \mathrm{mol} \mathrm{g}^{-1}$ fresh weight in leaves when the transformation was targeted to the cytosol and chloroplast, respectively (Sakamoto and Murata, 1998). While, the transformation of maize, an accumulator plant, with betA increased GB concentration to about $5.7 \mu \mathrm{mol} \mathrm{g}^{-1}$ fresh weight, a value higher than that present in wild-type (WT) maize plants under drought stress (Quan et al., 2004).

However, the efficacy of GB engineering for important cultured field crops has never been demonstrated. The main reason is that even if the levels of $\mathrm{GB}$ in the engineered plants were significantly increased, they were still lower than those of high accumulator species, which range from about 4 to $40 \mu \mathrm{mol} \mathrm{g}{ }^{-1}$ fresh weight (Rhodes and Hanson, 1993; Sakamoto and Murata, 2002). One possible explanation for this is that choline availability may limit GB accumulation in some plants. In fact, transformed tobacco plants, with a spinach cDNA encoding $C M O$, showed a very low GB production of about $0.02-0.05 \mu \mathrm{mol} \mathrm{g}{ }^{-1}$ fresh weight in both control and salt stress conditions, and were able to accumulate large amounts of GB only when choline was supplemented (Nuccio et al., 1998). Moreover, the concentration of endogenous choline did not change significantly in all transgenic plants expressing the $\operatorname{cod} A$ gene (Giri, 2011). Its availability does not affect the GB synthesis of all transgenic plants, most probably due to synergism in the demand and supply of choline to chloroplast.

In fact, the cytosolic choline in plants, synthetized in the cytosol or exogenously supplied, needs to be transported to the chloroplast for GB biosynthesis. Therefore, it could be 
possible that different capacities of plants to synthetize GB, could be also dependent on their diverse ability to transport choline to the chloroplast and not only on its availability in the cytosol (McNeil et al., 2000; Khan et al., 2009). Besides, transformed tobacco plants overexpressing $\mathrm{CHO}$ in the chloroplast and supplemented with choline, accumulated GB at only $1 \mu \mathrm{mol} \mathrm{g}{ }^{-1} \mathrm{FW}$, while Arabidopsis which over expressed $\mathrm{CHO}$ in the cytosol and were supplemented with choline, accumulated GB at about $120 \mu \mathrm{mol} \mathrm{g}$ FW (Huang et al., 2000; Fariduddin et al., 2013). Similarly, CHO-transgenic tomato plants were able to accumulate more GB in the cytosol than in the chloroplast (Park et al., 2007). CHO-transgenic maize and rice were able to accumulate similar amounts of GB in both subcellular compartments, confirming that, independent of choline concentration in the cytosol, its species-specific capacity of transport from the cytosol to the chloroplast, highly affects GB production in the chloroplast and the plants tolerance to stress (Khan et al., 2009).

Several plant species engineered to express CMO and/or $\mathrm{BADH}$ and which are supplemented with $10 \mathrm{mM}$ betaine aldehyde, are able to synthesize GB in amounts comparable to accumulator plants (Chen and Murata, 2011). Specifically, $N$. tabacum, O. sativa and Daucus carota, transformed with betB and supplemented with betaine aldehyde, were able to produce 4.6, 6, and $10 \mu \mathrm{mol} \mathrm{g}^{-1}$ fresh weight GB (Kishitani et al., 2000; Kumar et al., 2004; Yang et al., 2007), demonstrating that a significant increase of GB is achievable.

Recently, a novel gene, GB1, differentially expressed in low and high GB accumulating genotypes of maize, was identified by Castiglioni et al. (2018). Transgenic GB1-maize and soybean lines accumulated GB at concentrations 4-10-fold higher than WT plants. GB1 protein is a member of the Pfam fatty acid hydroxylase superfamily, with a suggested peroxisomal location. Its predicted sequence showed $60 \%$ identity as a putative C-4 sterol methyl oxidase from rice. GB1 protein certainly has a main role in the GB accumulation in plants, and can be used as an innovative tool to improve tolerance to abiotic stress in crop plants (Castiglioni et al., 2018).

\section{EXOGENOUS GB APPLICATIONS}

Glycine betaine improves growth and survival of plants counteracting metabolic dysfunctions caused by stress. Due to the beneficial effects of GB, numerous experiments of exogenous application of this compatible compound, on lowaccumulator and non-accumulator plant species have been done. Recent studies, and related reports have proven its effectiveness in increasing plant tolerance to various stresses (Table 1). Exogenous GB is able to preserve Photosystem II (PSII) and the photosynthetic oxygen evolving complex (OEC) association under salinity in Lycopersicon esculentum (Mäkelä et al., 1998, 1999; Park et al., 2006), H. vulgare (Oukarroum et al., 2012) and N. tabacum (Ma X.L. et al., 2006), and to induce the expression of oxidative stress response genes, decreasing ROS accumulation and lipid peroxidation in cultured tobacco cells under salinity (Demiral and Türkan, 2004; Banu et al., 2010). Application of
GB to bread wheat leaves, reduces the accumulation of $\mathrm{Na}^{+}$and increases the accumulation of $\mathrm{K}^{+}$and $\mathrm{Ca}^{2+}$, improves leaf water potential, enhances the activities of SOD, CAT and POD and, reduces photoinhibition enhancing growth and yield (Ma Q.-Q. et al., 2006; Raza et al., 2007, 2014).

Khan et al. (2014) showed that salicylic acid induced GB accumulation in Vigna radiata under salinity, with a consequent increase of glutathione, reduction of ethylene and oxidative stress, and improvement of photosynthesis. GB also protects photosynthesis by modifying the lipid composition of the thylakoid membranes in Triticum aestivum (Zhao et al., 2007). It increases soluble sugars and free amino acid accumulation to protect plant cells from salinity- and drought-induced osmotic stress in Vigna unguiculata (Manaf, 2016), Phaseolus vulgaris (Osman and Salim, 2016), and Pisum sativum (Osman, 2015). GB specifically increases its own content and improves the activity of antioxidant enzymes and metabolites, such as SOD, CAT, APX, proline and $\gamma$-amino butyric acid (GABA), reducing $\mathrm{H}_{2} \mathrm{O}_{2}$ and malondialdehyde (MDA) in Prunus persica (Shan et al., 2016), Lolium perenne (Hu et al., 2012), Glycine max (Malekzadeh, 2015), and O. sativa (Yao et al., 2016).

DNA microarrays performed to study the gene expression modification induced by the application of exogenous GB $(100 \mathrm{mM})$ to Arabidopsis leaves and roots, revealed that the expression of genes encoding enzymes involved in ROS scavenging, as well as gene encoding functions related to membrane trafficking (RabA4c GTPase) and to extracellular ferric reduction (FRO2 and FRO4), was prevalently enhanced. This evidenced the involvement of stress-induced ROS signaling in GB action (Einset and Connolly, 2009) (Figure 2).

However, the GB applied to roots is usually taken up and accumulated in the cytosol and only a small amount is translocated to chloroplasts, while, when applied to leaves, it is translocated to meristematic tissues, in particular flower buds and shoot apices, and then translocated to actively growing and expanding tissues (Mäkelä et al., 1996; Park et al., 2006). Ladyman et al. (1980) also found that after the application of GB to mature leaves of $H$. vulgare under water stress, osmolytes were translocated to the young expanding tissues. Therefore, in plants even if GB is applied to old or mature tissues, it reallocates to young actively growing tissues, where its protective functions are mainly required.

\section{GLYCINE BETAINE TRANSPORT AND TRANSLOCATION}

Although it is clear that GB endogenously accumulated or exogenously applied is reallocated in growing expanding tissues, knowledge on glycine transport and translocation remains fragmentary (Masood et al., 2016), and to date no specific transporters for GB have been reported in plants (Chen and Murata, 2011; Kumar et al., 2017).

The first direct demonstration of a GB transport activity was obtained by Schwacke et al. (1999) through the heterologous expression of a tomato gene, homologous to Arabidopsis proline trasporter LeProT1 (Rentsch et al., 1996), in the yeast mutant 
TABLE 1 | Effect of exogenous GB under abiotic stress conditions.

\begin{tabular}{|c|c|c|c|}
\hline Crop & Abiotic stress & Effect of exogenous GB under abiotic stress conditions & Reference \\
\hline Brassica napus & Osmotic stress & $\begin{array}{l}\text { Inhibition of osmo-induced proline response, inhibitory effect on protein } \\
\text { synthesis }\end{array}$ & Gibon et al., 1997 \\
\hline Brassica rapa & Drought and salt stress & $\begin{array}{l}\text { Increased net photosynthesis, increased stomatal conductance, decrease } \\
\text { of photorespiration }\end{array}$ & Mäkelä et al., 1999 \\
\hline Glycine max & Salt stress & $\begin{array}{l}\text { Reduced lipid peroxidation (MDA content), increased proline content of } \\
\text { seedlings, increased CAT and APX enzyme activity, reduced ROS level, } \\
\text { reduced } \mathrm{Na}^{+} / \mathrm{K}^{+} \text {ratio }\end{array}$ & Malekzadeh, 2015 \\
\hline Hordeum vulgare & Cold stress & $\begin{array}{l}\text { Increase in total osmolality, higher endogenous GB levels, induction of } \\
\text { wcor410 and wcor413 genes, improved tolerance to photoinhibition of PSII }\end{array}$ & Allard et al., 1998 \\
\hline Hordeum vulgare & Heat stress & $\begin{array}{l}\text { Increase tolerance of PSII and protective effect on the OEC (oxygen } \\
\text { evolving complex) }\end{array}$ & Oukarroum et al., 2012 \\
\hline Lolium perenne & Salt stress & $\begin{array}{l}\text { Higher shoot and root fresh weight, lower decline of RWC and Chl, reduced } \\
\text { electrolyte leakage and MDA content, increased GB content, SOD, CAT } \\
\text { and APX activity, reduced } \mathrm{Na}^{+} / \mathrm{K}^{+} \text {ratio in leaves and stems }\end{array}$ & Hu et al., 2012 \\
\hline Lycopersicon esculentum & Cold stress & $\begin{array}{l}\text { Higher PSIl activity, lower } \mathrm{H}_{2} \mathrm{O}_{2} \text { levels, increased catalase activity and } \\
\text { catalase gene (CAT1) expression }\end{array}$ & Park et al., 2006 \\
\hline Lycopersicon esculentum & Drought and salt stress & $\begin{array}{l}\text { Increased net photosynthesis and stomatal conductance, decrease of } \\
\text { photorespiration }\end{array}$ & Mäkelä et al., 1999 \\
\hline Lycopersicon esculentum & Salt and heat stress & Increased fruit yield, increased rate of net photosynthesis & Mäkelä et al., 1998 \\
\hline Medicago sativa & Cold stress & Reduced loss of ions from the shoot tissues & Zhao et al., 1992 \\
\hline Nicotiana tabacum & Drought stress & $\begin{array}{l}\text { Improved growth of plants, improved osmotic adjustment, enhanced } \\
\text { photosynthesis, higher efficiency of PSII, increased anti-oxidative enzyme } \\
\text { activities }\end{array}$ & Ma et al., 2007 \\
\hline Oryza sativa & Salt stress & $\begin{array}{l}\text { Improved height, fresh weight and dry weight in plant, enhanced total } \\
\text { chlorophyll and proline content, reduced MDA content }\end{array}$ & Yao et al., 2016 \\
\hline Phaseolus vulgaris & Salt stress & $\begin{array}{l}\text { Higher plant fresh weight, increased values of leaf area ratio, leaf area index, } \\
\text { RWC and MSI (Membrane Stability Index), higher total soluble sugar and } \\
\text { free amino acids concentrations in the leaves and pods }\end{array}$ & Osman and Salim, 2016 \\
\hline Pisum sativum & Drought stress & $\begin{array}{l}\text { Enhanced growth, pods and leaves number per plant, increased level of } \\
\text { soluble sugars, higher free amino acids and soluble proteins in leaves, } \\
\text { increased activity of antioxidant enzymes, reduction of proline accumulation }\end{array}$ & Osman, 2015 \\
\hline Prunus persica & Cold storage & $\begin{array}{l}\text { Lower content of MDA, higher level of endogenous GB, increased activity of } \\
\text { BADH, P5CS and OAT, increased GABA content, higher level of ATP } \\
\text { content }\end{array}$ & Shan et al., 2016 \\
\hline Solanum lycopersicum & Drought stress & Improved yield & Jokinen et al., 1999 \\
\hline Triticum aestivum & Cold stress & $\begin{array}{l}\text { Increase in total osmolality, higher endogenous GB levels, induction of } \\
\text { wcor410 and wcor413 genes, improved tolerance to photoinhibition of PSII }\end{array}$ & Allard et al., 1998 \\
\hline Triticum aestivum & Drought stress & Increased grain yield and higher number of grains per spike & Díaz-Zorita et al., 2001 \\
\hline Triticum aestivum & Drought stress & $\begin{array}{l}\text { Improved STI (Stress tolerance index), enhanced levels of osmolytes } \\
\text { (proline and GB), increased RWC }\end{array}$ & Gupta et al., 2014 \\
\hline Triticum aestivum & Drought stress & $\begin{array}{l}\text { Higher net photosynthetic rate, higher maximal photochemistry efficiency of } \\
\text { PSII, higher antioxidativeenzyme activities }\end{array}$ & Ma X.L. et al., 2006 \\
\hline Triticum aestivum & Drought stress & $\begin{array}{l}\text { Increased spike length, higher number of spikelets per spike and of grains, } \\
\text { improved yield, higher leaf turgor potential }\end{array}$ & Raza et al., 2014 \\
\hline Triticum aestivum & Drought stress & $\begin{array}{l}\text { Stabilization of the function of the thylakoid membranes, suppression of } \\
\text { chlorophyll degradation and enhancement of } \mathrm{Ca}^{2+} \text {-ATPase and Hill } \\
\text { reaction activities, improved lipid composition of the thylakoid membranes }\end{array}$ & Zhao et al., 2007 \\
\hline Triticum aestivum & Salt stress & $\begin{array}{l}\text { Higher endogenous GB levels, improved leaf water and osmotic potential, } \\
\text { reduced } \mathrm{Na}^{+} \text {and increased } \mathrm{K}^{+} \text {and } \mathrm{Ca}^{2+} \text {, improved growth, enhanced } \\
\text { activities of } \mathrm{SOD}, \mathrm{CAT} \text {, and } \mathrm{POD}\end{array}$ & Raza et al., 2007 \\
\hline Triticum aestivum & Salt stress & Alleviated inhibition of photosynthesis & Rajasekaran et al., 1997 \\
\hline Vigna unguiculata & Salt stress & $\begin{array}{l}\text { Increased total soluble sugar concentration and antioxidative enzymes } \\
\text { (POD and PAL), increment of proline }\end{array}$ & Manaf, 2016 \\
\hline Zea mays & Cold stress & $\begin{array}{l}\text { Prevention of chlorosis and reduced lipid peroxidation of the cell } \\
\text { membranes }\end{array}$ & Chen et al., 2000 \\
\hline Zea mays & Drought stress & Increased height, leaf area and total dry weight & Reddy et al., 2013 \\
\hline
\end{tabular}




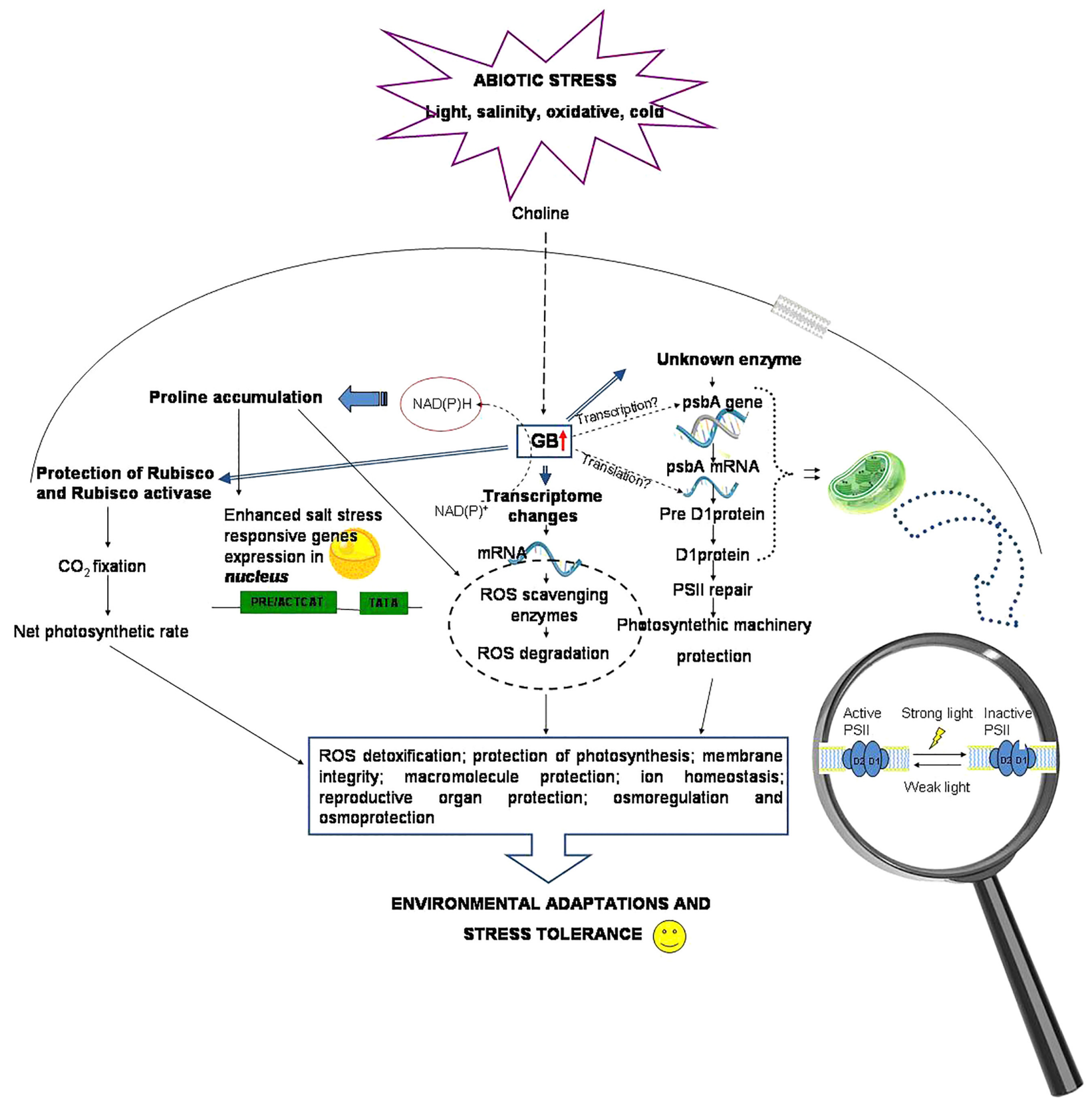

FIGURE 2 | Glycine betaine mechanisms and protective roles via the ROS scavenging system.

22574d. The latter was unable to grow on citrulline, proline, or GABA as the sole nitrogen source; however, when complemented with the LeProT1 protein, it was able to transport proline and GABA with a low affinity and GB with a high affinity. Breitkreuz et al. (1999) also found that the Arabidopsis GABA transporter ProT2 was strongly inhibited by GB, with a high affinity to the osmolytes. ProTs could therefore be considered general carriers, which allow the transport of compatible solutes, including $\mathrm{GB}$, with stress protecting functions (Breitkreuz et al., 1999). However, Waditee et al. (2002) showed that in the betaineaccumulating mangrove, Avicennia marina under salinity
LeProT1 mRNA accumulated only in pollen; while in other tissues there was an increase of mRNA for GB/proline A. marina transporters 1, 2, and $3(A m T 1,-2$, and -3). AmT1 and -2 were able to complement salt-sensitive GB and a proline-deficient E. coli mutant. Moreover, the main accumulation of AmT1 under salinity was correlated to a major role for the transport of GB under osmotic stress. Subsequently, a gene homologous to AmT1, BvBet/ProT1, was isolated in Beta vulgaris by Yamada et al. (2009). A fusion protein GFP-BvBet/ProT1 was used to show the plasma membrane localization of the protein. In addition, both under control and salt-stress conditions, higher levels of CMO and 
$B v B e t / P r o T 1$ mRNA were found in older leaves than in young leaves, further demonstrating that GB is mainly synthesized in older tissues and then translocated to young expanding ones (Yamada et al., 2009). In situ hybridization experiments demonstrated that BvBet/ProT1 was localized in phloem and xylem parenchyma cells (Yamada et al., 2011). A comparison between Bet/ProTs from non-accumulating (A. thaliana ColO) and GB accumulating (B. vulgaris, Amaranthus tricolor, and Atriplex gmelinii) plants expressed in a yeast mutant deficient for uptake of proline and GB, showed that all the transporters had lower $\mathrm{Km}$ and therefore a higher affinity for GB than proline. The uptake of both osmolytes was $\mathrm{pH}$-dependent, with $\mathrm{GB}$ uptake at a higher rate by BvBet/ProT1 when the $\mathrm{pH}$ decreased to 4.5 and underwent an inhibition by the proton uncoupler carbonylcyanide m-chlorophenylhydrazone (CCCP). The same transporters exhibited a higher affinity for choline uptake rather than $\mathrm{GB}$, particularly at higher $\mathrm{pH}$ (6.5), and were less dependent on the inhibitor CCCP, suggesting that Pro/BetTs enacts a symport mechanism for $\mathrm{GB} / \mathrm{H}^{+}$and choline $/ \mathrm{H}^{+}$with a different mechanism of proton binding (Yamada et al., 2011).

Tsutsumi et al. (2015), which localized CMO exclusively in mature leaves of $A$. gmelinii, found that in the same plants the BetT gene was expressed in bladder and stalk cells, in meso-phyll cells of young leaf laminae and in vascular tissues. This finding is in agreement with the translocation experiments of ${ }^{14} \mathrm{C}$-labeled GB in $H$. vulgare (Ladyman et al., 1980), Brassica rapa ssp. oleifera, Glycine max, Pisum sativum, Lycopersicon esculentum, and T. aestivum (Mäkelä et al., 1996) which suggested a long-distance translocation of GB, together with photosynthetic assimilates, via phloem, and the phloem localization of BvBet/ProT1 found by Yamada et al. (2011). Moreover, Park et al. (2006) demonstrated that when GB was applied to single mature leaves of tomato and accumulated in them, soon after, a large part of it was translocated to meristematic tissues, such as flower buds and shoot apices. In Arabidopsis (Sulpice et al., 2003) and tomato (Park et al., 2007) GB-accumulating transgenic plants also translocated GB, via phloem, actively accumulating it in growing flower buds and shoot apices.

Tsutsumi et al. (2015) suggested that one possible explanation for why GB is firstly synthetized in expanded tissues and then transported to young expanding ones, is that for its synthesis it is necessary to reduce ferredoxin, which is primarily produced by mature leaves.

\section{GLYCINE BETAINE ROLE IN ABIOTIC STRESS TOLERANCE IN PLANTS}

Glycine betaine is one of the main compatible compounds present in Poaceae and Chenopodiaceae under salinity, and which is also involved in many other protective mechanisms against stress-related plant disorders (Ashraf and Foolad, 2007; Chen and Murata, 2008; Banu et al., 2010; Carillo et al., 2011; Khan et al., 2012). GB is an amphoteric metabolite highly soluble in water, and electrically neutral over a vast range of $\mathrm{pH}$ values (D'Amelia et al., 2018). The cellular concentration of $\mathrm{GB}$, proline, or both, contribute to the osmotic pressure as a whole in many halophyte plants (Flowers et al., 1977). In glycophytes, GB is present at much lower levels than in halophytes. However, since it is compartmentalized solely to the cytosol and hyaloplasmic organelles, which account for about $20 \%$ of the volume of the cell or less, it is able to significantly contribute to the increase of osmotic pressure and can balance the vacuolar osmotic potential (Ashraf and Foolad, 2007; Cuin et al., 2009; Carillo et al., 2019). GB does not only act as an osmolyte for osmotic adjustment, but, as a zwitterion, it can interact with both hydrophilic and hydrophobic domains of protein complexes and membranes: this contributes to stabilizing and maintaining the structural and functional integrity of these molecules, protecting them from the detrimental effects of highly reactive oxygen species (ROS) (Sharma and Dietz, 2006; Ashraf and Foolad, 2007; Chen and Murata, 2008; Islam et al., 2009; Banu et al., 2010; Gupta and Huang, 2014). GB can reduce the salt-induced potassium efflux by regulating ion channels (Wei et al., 2017), and enhancing the enzymatic activity of plasma membrane $\mathrm{H}^{+}$-ATPase, increasing the phosphate uptake and regulating the phosphate homeostasis ( $\mathrm{Li}$ et al., 2019). Furthermore, it is able to preserve the thermodynamic stability of macromolecules, reversing protein misfolding and/or aggregation without compromising their native functional activities (Khan et al., 2010). When GB is present at high levels, together with proline, it is so efficient in protecting plants by oxidative stress that antioxidant metabolites and enzymes play a minor role in ROS protection under salinity (Carillo et al., 2011; Annunziata et al., 2017; Woodrow et al., 2017).

Several beneficial effects of GB are summarized in Figure 2 and Table 2.

It has been proven that the synthesis of GB is ontogenetically controlled in several plant species (Table 3). However, in bread wheat and durum wheat, it is asynchronous compared to that of proline and independent of nitrogen nutrition (Colmer et al., 1995; Carillo et al., 2008, 2011). In fact, GB is synthetized and accumulated in young leaf tissues during prolonged stress, and, as a quaternary nitrogen compound, its synthesis is independent of nitrate nutrition. Whereas, proline is accumulated more rapidly at the onset of stress and primarily in older leaves dependent on high nitrate (Carillo et al., 2008) (Figure 3). The lack of nitrogen nutrition influence on GB synthesis and accumulation, implies that nitrogen reserves within the plant can be employed to fulfill the metabolic demands of osmolytes, resulting from salt stress (Carillo, 2018). Therefore, GB and soluble sugars, like sucrose, but not proline, can play a major role in a plants adaptation to salinity under low nitrogen treatments; while proline is promptly synthetized, also in young tissues, under high nitrogen supply (Annunziata et al., 2017). However, GB and proline levels are highly correlated under salinity conditions, and their sum is equal in young expanding tissues of both high- and low-nitrogen grown plants. The presence of interchangeable levels of both compounds in young tissues, independent of nitrogen nutrition, would imply that resources are allocated in growing tissues in order to support and protect young growing tissues (Carillo et al., 2008). The fact that the presence of one of these metabolites limits that 
TABLE 2 | Effect of endogenous glycine betaine under abiotic stress conditions.

\begin{tabular}{|c|c|c|c|}
\hline Crop & Abiotic stress & $\begin{array}{l}\text { Effect of endogenous GB under abiotic stress } \\
\text { conditions }\end{array}$ & Reference \\
\hline Amaranthus tricolor & Salt stress & Osmotic adaptation to salinity & Wang and Nii, 2000 \\
\hline Beta vulgaris & Water stress & Osmotic adjustment & Chołuj et al., 2008 \\
\hline Hordeum vulgare & Cold stress & Improved survival of leaf laminae & Kishitani et al., 1994 \\
\hline Spinacia oleracea & Salt stress & Control of cellular osmotic potential & Di Martino et al., 2003 \\
\hline Morus alba & Salt stress & Osmotic adjustment & Agastian et al., 2000 \\
\hline Oryza sativa & Drought stress & $\begin{array}{l}\text { Maintenance of } \mathrm{RWC} \text { and } \mathrm{GSH} / \mathrm{GSSG} \text { ratio, lower } \\
\text { reduction of } \mathrm{K}^{+}, \mathrm{Ca}^{2+} \text {, and } \mathrm{Mg}^{2+} \text { content }\end{array}$ & Basu et al., 2010 \\
\hline Triticum aestivum & Cold stress & Protection of plasma membrane & Zhang et al., 2010 \\
\hline Triticum aestivum L. cv. Glenlea & Freezing stress & Increased freezing tolerance & Allard et al., 1998 \\
\hline Triticum aestivum & Salt stress & $\begin{array}{l}\text { Higher RWC and higher activity of antioxidant enzymes } \\
\text { such as SOD, GR, and CAT }\end{array}$ & Sairam et al., 2002 \\
\hline Triticum durum & Salt stress & $\begin{array}{l}\text { Function as osmolyte to balance water potential within root } \\
\text { and shoot tissues }\end{array}$ & Carillo et al., 2005 \\
\hline Triticum durum & Salt stress & $\begin{array}{l}\text { Protection of photosynthesis, increased nitrogen } \\
\text { metabolism enzyme activities and ROS scavenging in } \\
\text { young leaf tissues }\end{array}$ & Carillo et al., 2008, 2011 \\
\hline Triticum durum & Salt stress & $\begin{array}{l}\text { Osmotic adjustment of root tissues of plants grown under } \\
\text { low nitrate and salinity }\end{array}$ & Annunziata et al., 2017 \\
\hline
\end{tabular}

TABLE 3 | Spatial accumulation of endogenous glycine betaine.

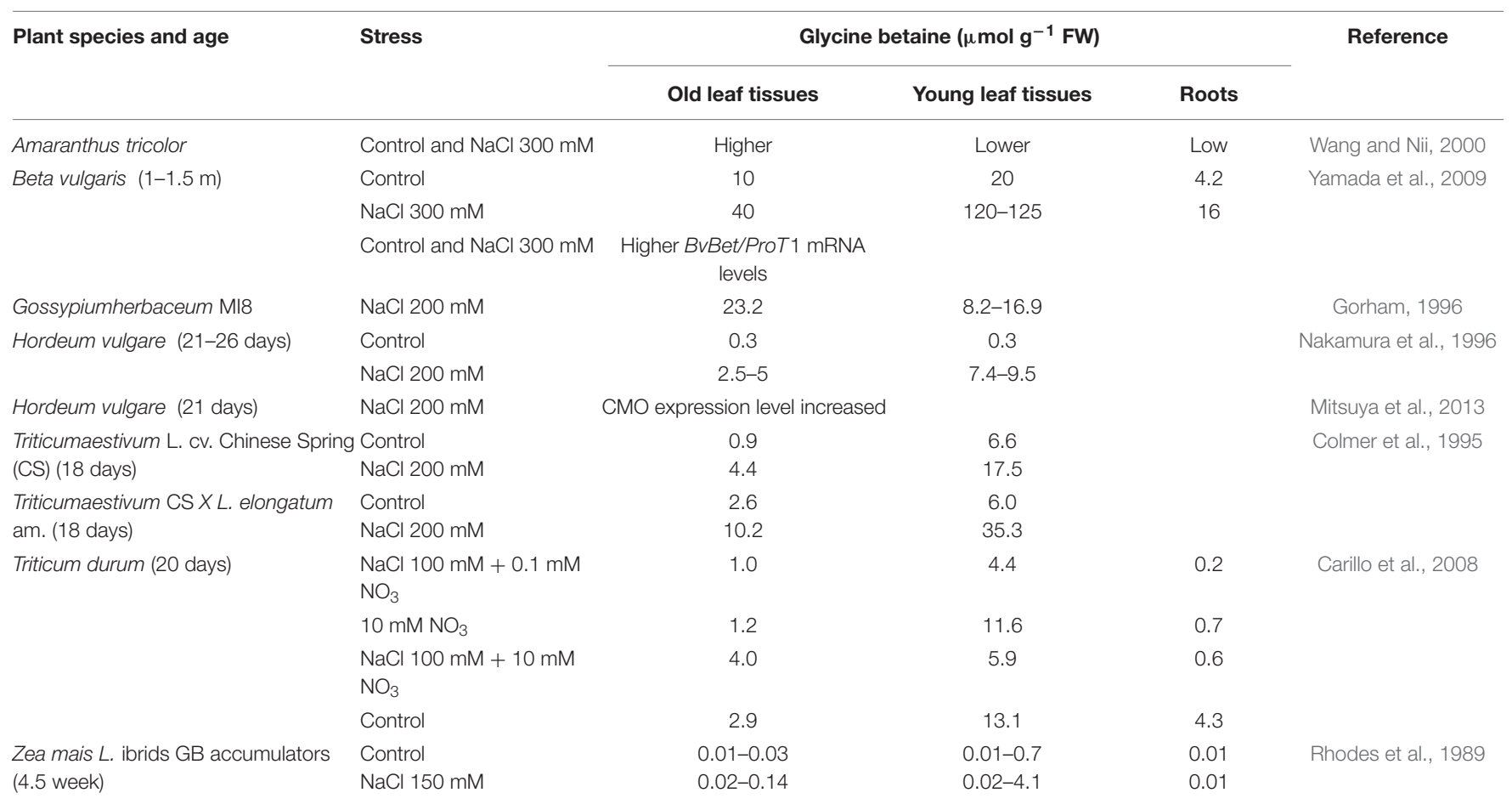




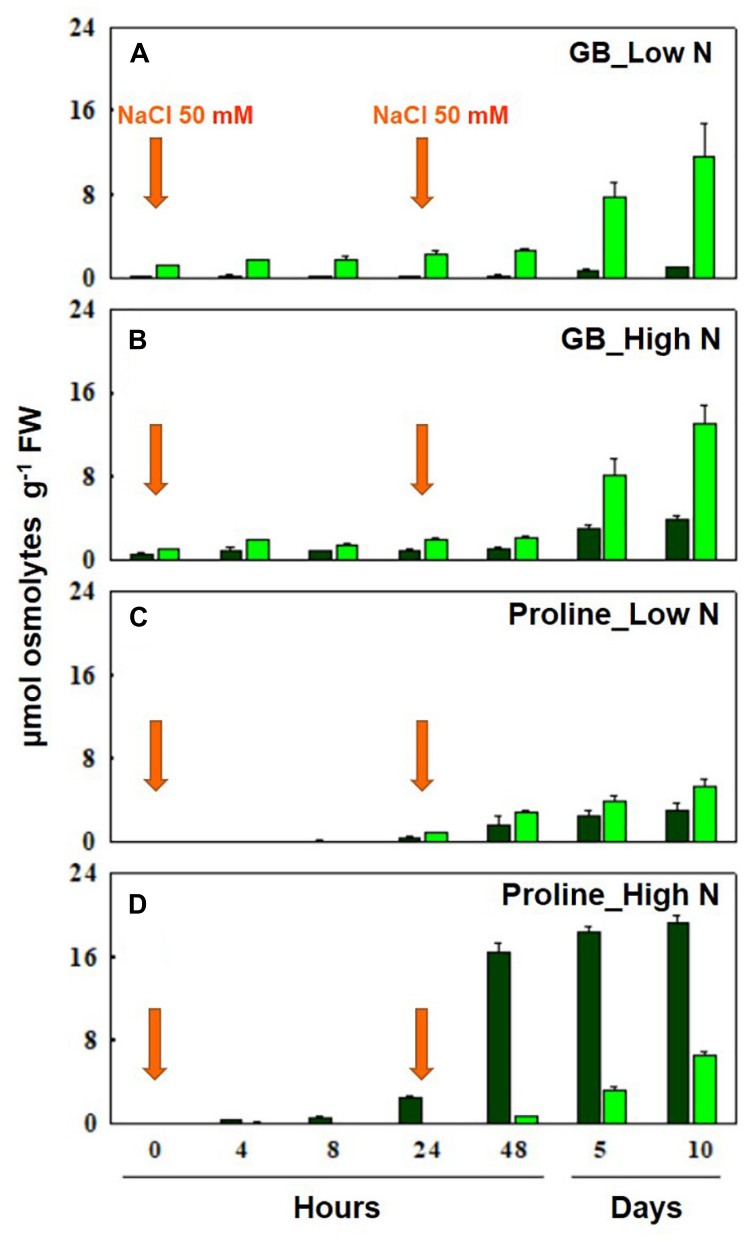

FIGURE 3 | Accumulation of GB at low (A) and high (B) N, and proline at low (C) and high (D) $\mathrm{N}$ leaves of durum wheat plants after 10 days of hydroponic culture $(0 \mathrm{~h})$ and after $4,8,24,48 \mathrm{~h}, 5$ and 10 days of salt treatment. $\mathrm{NaCl}$ $50 \mathrm{mM}$ was added twice at 0 and $24 \mathrm{~h}$. Bar colors show older/mature (dark green) and younger (light green) tissues. Nitrate 0.1 (low N) or 10 mM (high N) was added on day 5 of hydroponic culture. The values are mean \pm SD $(n=4)$ (data from Carillo et al., 2008, 2011).

of the other could also be due to the proposed GB-dependent inhibition of proline accumulation (Gibon et al., 1997; Sulpice et al., 1998). However, the data of Carillo et al. (2008) conflict with this assumption since they showed that the synthesis and accumulation of proline antedate those of GB, and that the use of an inhibitor of proline synthesis, hydroxyl-proline, decreases GB accumulation.

Rhodes and Hanson (1993) found that plants do not show a significant GB breakdown. Therefore, the low levels of GB present in older plant tissues depend on a dilution mechanism that occurs via GB translocation from fully expanded to young growing tissues, since the latter is more prone to stress, as reported in oilseed rape, turnip rape, bread, and durum wheat (Maas and Poss, 1989; Mäkelä et al., 1996; Carillo et al., 2008). Annunziata et al. (2017) also found that the contribution of GB to osmotic adjustment in younger tissues is much higher than that in older tissues, independently of nitrogen nutrition. Even the expression level of CMO (Mitsuya et al., 2013) and BADH (Hattori et al., 2009) proteins was preferentially induced in younger leaves in barley plants under salinity. Since GB is accumulated only during prolonged stresses, and it cannot be metabolized, even if easily and efficiently transported from older to younger plant tissues, it has been supposed that it can play a pivotal role in protecting against salt stress young leaf and root tissues (Carillo et al., 2008, 2011). In view of this, Annunziata et al. (2017) ascribed the arrest of growth and differentiation of root tips of durum wheat under salinity to the delay in the synthesis of GB, which did not allow for the prompt contrast of the cytotoxic effect of the $\mathrm{NaCl}$ ions.

Carillo (2018) suggested that in young leaves of durum wheat plants, under high salinity the salt induced stomata closure restricts $\mathrm{CO}_{2}$ exchange and, consequently, reduces the RUBISCO $\mathrm{CO}_{2}$-fixation activity, while increasing the overexcitation of the photosynthetic apparatus and the production of ROS. In this condition, GB synthesis is induced to increase the protection of the photosynthetic apparatus (Chen and Murata, 2011; Kurepin et al., 2015).

Nevertheless, Carillo et al. (2011) showed that the relevance of GBs synthesis in durum wheat, is almost completely inhibited by high light (HL) even in the presence of high concentrations of $\mathrm{NaCl}$. Woodrow et al. (2017) proved that in these plants, in which GB was not accumulated, the fine metabolic regulation of few specific primary metabolites, such as GABA, amides, minor amino acids and hexoses, could play a key role in the plants response to simultaneous stresses. The positive effect of GABA can be ascribed to its proton consuming synthesis that allows for the control of $\mathrm{pH}$, and its nature of zwitterion which permits its accumulation in cytosol, where it acts as an osmolyte and ROS scavenger, without toxic effects. However, a possible more relevant effect is that its synthesis, operated by the glutamate decarboxylase (GAD), releases $\mathrm{CO}_{2}$ that can be used for RUBISCO and the simultaneous dissipation of excess energy produced by photosynthesis under HL and salinity. This re-start of the Calvin cycle reduces the pressure on the photosynthetic electron chain and decreases ROS production and photodamage (Carillo, 2018, and references therein).

\section{CONCLUSION}

Metabolic engineering approaches and exogenous applications, aimed at increasing the synthesis and/or accumulation of GB in plants tissues, have been associated with the improvement in growth and survival of plants, ROS scavenging, osmoregulation of the cytosolic compartments, membrane stabilization, buffering of redox potential and induction of stress responsive genes that counteract the metabolism dysfunctions caused by stress. However, the efficacy of GB metabolism transformation for plant crops, cultured in field, has not been fully demonstrated. This might be because even if the GB concentration in transformed plants is significantly increased, it is still lower than that of a natural high accumulator species. Moreover, even if exogenous applications of GB that is targeted to the older damaged 
tissues has been tested, GB is promptly re-translocated to younger expanding tissues, where its protective functions are likely most required.

However, what is certainly clear is that in addition to this spatial discrepancy, that is the accumulation or re-allocation to young tissues after exogenous application, the synthesis of GB is also temporally delayed compared to other important osmolytes, such as proline. This most likely happens because GB cannot be metabolized. It is synthesized and accumulated only during extended stress, particularly in young tissues, as well as at low $\mathrm{N}$ nutrition. For this reason, it has been supposed that it plays a pivotal role in protecting young expanding tissues.

\section{REFERENCES}

Agastian, P., Kingsley, S. J., and Vivekanandan, M. (2000). Effect of salinity on photosynthesis and biochemical characteristics in mulberry genotypes. Photosynthetica 38, 287-290. doi: 10.1023/A:100726693

Allard, F., Houde, M., Kröl, M., Ivanov, A., Huner, N. P. A., and Sarhan, F. (1998). Betaine improves freezing tolerance in wheat. Plant Cell Physiol. 39, 1194-1202. doi: 10.1093/oxfordjournals.pcp.a029320

Annunziata, M. G., Ciarmiello, L. F., Woodrow, P., Maximova, E., Fuggi, A., and Carillo, P. (2017). Durum wheat roots adapt to salinity remodeling the cellular content of nitrogen metabolites and sucrose. Front. Plant Sci. 7:2035. doi: 10.3389/fpls.2016.02035

Ashraf, M., and Foolad, M. R. (2007). Roles of glycine betaine and proline in improving plant abiotic stress resistance. Environ. Exp. Bot. 59, 206-216. doi: 10.1016/j.envexpbot.2005.12.006

Banu, M. N. A., Hoque, M. A., Watanabe-Sugimoto, M., Islam, M. M., Uraji, M., Matsuoka, K., et al. (2010). Proline and glycinebetaine ameliorated $\mathrm{NaCl}$ stress via scavenging of hydrogen peroxide and methylglyoxal but not superoxide or nitric oxide in tobacco cultured cells. Biosci. Biotechnol. Biochem. 74, 2043-2049. doi: 10.1271/bbb.100334

Basu, S., Roychoudhury, A., Paromita Saha, P., and Sengupta, D. (2010). Comparative analysis of some biochemical responses of three indica rice varieties during polyethylene glycol-mediated water stress exhibits distinct varietal differences. Acta Physiol. Plant. 32, 551-563. doi: 10.1007/s11738-0090432-y

Bhuiyan, N. H., Hamada, A., Yamada, N., Rai, V., Hibino, T., and Takabe, T. (2007). Regulation of betaine synthesis by precursor supply and choline monooxygenase expression in Amaranthus tricolor. J. Exp. Bot. 58, 4203-4212. doi: $10.1093 / \mathrm{jxb} / \mathrm{erm} 278$

Breitkreuz, K. E., Shelp, B. J., Fischer, W. N., Schwacke, R., and Rentsch, D. (1999). Identification and characterization of GABA, proline and quaternary ammonium compound transporters from Arabidopsis thaliana. FEBS Lett. 450, 280-284. doi: 10.1016/S0014-5793(99)00516-5

Brendza, K. M., Haakenson, W., Cahoon, R. E., Hicks, L. M., Palavalli, L. H., Chiapelli, B. J., et al. (2007). Phosphoethanolamine N-methyltransferase (PMT1) catalyses the first reaction of a new pathway for phosphocholine biosynthesis in Caenorhabditis elegans. Biochem. J. 404, 439-448. doi: 10.1042/bj20061815

Carillo, P. (2018). GABA shunt in durum wheat. Front. Plant Sci. 9:100. doi: 10.3389/fpls.2018.00100

Carillo, P., Cirillo, C., De Micco, V., Arena, C., De Pascale, S., and Rouphael, Y. (2019). Morpho-anatomical, physiological and biochemical adaptive responses to saline water of Bougainvillea spectabilis Willd. trained to different canopy shapes. Agric. Water Manage. 212, 12-22. doi: 10.1016/j.agwat.2018.08.037

Carillo, P., Mastrolonardo, G., Nacca, F., and Fuggi, A. (2005). Nitrate reductase in durum wheat seedlings as affected by nitrate nutrition and salinity. Funct. Plant Biol. 32, 209-219. doi: 10.1071/FP04184

Carillo, P., Mastrolonardo, G., Nacca, F., Parisi, D., Verlotta, A., and Fuggi, A. (2008). Nitrogen metabolism in durum wheat under salinity: accumulation of proline and glycine betaine. Funct. Plant Biol. 35, 412-426. doi: 10.1071/ FP08108

Carillo, P., Parisi, D., Woodrow, P., Pontecorvo, G., Massaro, G., Annunziata, M. G., et al. (2011). Salt-induced accumulation of glycine betaine is inhibited

\section{AUTHOR CONTRIBUTIONS}

All authors listed have made a substantial, direct and intellectual contribution to the work, and approved it for publication.

\section{FUNDING}

This study was supported by the Max Planck Society, MIURDAAD Project No. 32983: the Italy-Germany Joint Mobility Program "Salinity tolerance and nitrogen use efficiency in durum wheat" and the University of Campania "Luigi Vanvitelli" Programma VALERE.

by high light in durum wheat. Funct. Plant Biol. 38, 139-150. doi: 10.1071/FP 10177

Castiglioni, P., Bell, E., Lund, A., Rosenberg, A. F., Galligan, M., Hinchey, B. S., et al. (2018). Identification of GB1, a gene whose constitutive overexpression increases glycinebetaine content in maize and soybean. Plant Direct. 2:e00040. doi: $10.1002 /$ pld 3.40

Chen, T., and Murata, N. (2011). Glycinebetaine protects plants against abiotic stress: mechanisms and biotechnological applications. Plant Cell Environ. 34, 1-20. doi: 10.1111/j.1365-3040.2010.02232.x

Chen, T. H. H., and Murata, N. (2008). Glycinebetaine: an effective protectant against abiotic stress in plants. Trends Plant Sci. 13, 499-505. doi: 10.1016/j. tplants.2008.06.007

Chen, W. P., Li, P. H., and Chen, T. H. H. (2000). Glycinebetaine increases chilling tolerance and reduces chilling-induced lipid peroxidation in Zea mays L. Plant Cell Environ. 23, 609-618. doi: 10.1046/j.1365-3040.2000.00570.x

Chołuj, D., Karwowska, R., Ciszewska, A., and Jasińska, M. (2008). Influence of long-term drought stress on osmolyte accumulation in sugar beet (Beta vulgaris L.) plants. Acta Physiol. Plant. 30, 679-687. doi: 10.1007/s11738-0080166-2

Ciarmiello, L. F., Di Maro, A., Woodrow, P., Annunziata, M. G., Kafantaris, I., Mirto, A., et al. (2018). Unveiling the enigmatic structure of TdCMO transcripts in durum wheat. Agronomy 8, 1-11. doi: 10.3390/agronomy8110270

Colmer, T. D., Epstein, E., and Dvorak, J. (1995). Differential solute regulation in leaf blades of various ages in salt-sensitive wheat and a salt-tolerant wheat $\mathrm{x}$ Lophopyrum elongatum (Host) A, Love Amphiploid. Plant Physiol. 108, 1715-1724. doi: 10.1104/pp.108.4.1715

Cuin, T. A., Tian, Y., Betts, S. A., Chalmandrier, R., and Shabala, S. (2009). Ionic relations and osmotic adjustment in durum and bread wheat under saline conditions. Funct. Plant Biol. 36:9051. doi: 10.1071/fp09051

D’Amelia, L., Dell'Aversana, E., Woodrow, P., Ciarmiello, L., and Carillo, P. (2018). "Metabolomics for crop improvement against salinity stress," in Salinity Responses and Tolerance in Plants, Vol. 2, eds V. Kumar, S. Wani, P. Suprasanna, and L. S. Tran (Cham: Springer).

Demiral, T., and Türkan, I. (2004). Does exogenous glycinebetaine affect antioxidative system of rice seedlings under $\mathrm{NaCl}$ treatment? J. Plant Physiol. 161, 1089-1100. doi: 10.1016/j.jplph.2004.03.009

Di Martino, C., Delfine, S., Pizzuto, R., Loreto, F., and Fuggi, A. (2003). Free amino acids and glycine betaine in leaf osmoregulation of spinach responding to increasing salt stress. New Phytol. 158, 455-463. doi: 10.1046/j.1469-8137. 2003.00770.x

Díaz-Zorita, M., Fernández-Canigia, M. V., and Grosso, G. A. (2001). Applications of foliar fertilizers containing glycinebetaine improve wheat yields. J. Agron. Crop Sci. 186, 209-215. doi: 10.1046/j.1439-037X.2001.00469.x

Einset, J., and Connolly, E. L. (2009). Glycine betaine enhances extracellular processes blocking ROS signaling during stress. Plant Signal. Behav. 4, 197-199. doi: $10.4161 /$ psb.4.3.7725

Fan, F., and Gadda, G. (2005). On the catalytic mechanism of choline oxidase. J. Am. Chem. Soc. 127, 2067-2074. doi: 10.1021/ja044541q

Fariduddin, Q., Varshney, P., Yusuf, M., Ali, A., and Ahmad, A. (2013). Dissecting the role of glycine betaine in plants under abiotic stress. Plant Stress 7, 8-18.

Ferchichi, S., Hessini, K., Dell'Aversana, E., D’Amelia, L., Woodrow, P., Ciarmiello, L. F., et al. (2018). Hordeum vulgare and Hordeum maritimum respond to 
extended salinity stress displaying different temporal accumulation pattern of metabolites. Funct. Plant Biol. 45, 1096-1109. doi: 10.1071/FP18046

Fitzgerald, T. L., Waters, D. L. E., and Henry, R. J. (2009). Betaine aldehyde dehydrogenase in plants. Plant Biol. 11, 119-130. doi: 10.1111/j.1438-8677. 2008.00161.x

Flowers, T. J., Troke, P. F., and Yeo, A. R. (1977). The mechanism of salt tolerance in halophytes. Annu. Rev. Plant Physiol. 28, 89-121. doi: 10.1146/annurev.pp. 28.060177.000513

Fujiwara, T., Hori, K., Ozaki, K., Yokota, Y., Mitsuya, S., Ichiyanagi, T., et al. (2008). Enzymatic characterization of peroxisomal and cytosolic betaine aldehyde dehydrogenases in barley. Physiol. Plant. 134, 22-30. doi: 10.1111/j.1399-3054. 2008.01122.x

Gao, M., Sakamoto, A., Miura, K., Murata, N., Sugiura, A., and Tao, R. (2000). Transformation of Japanese persimmon (Diospyros kaki Thunb.) with a bacterial gene for choline oxidase. Mol. Breed. 6, 501-510. doi: 10.1023/a: 1026513831290

Gibon, Y., Bessieres, M. A., and Larher, F. (1997). Is glycine betaine a noncompatible solute in higher plants that do not accumulate it? Plant Cell Environ. 20, 329-340. doi: 10.1046/j.1365-3040.1997.d01-82.x

Giri, J. (2011). Glycinebetaine and abiotic stress tolerance in plants. Plant Signal. Behav. 6, 1746-1751. doi: 10.4161/psb.6.11.17801

Gorham, J. (1996). Glycinebetaine is a major nitrogen-containing solute in the Malvaceae. Phytochemistry 43, 367-369. doi: 10.1016/0031-9422(96)00312-3

Gupta, B., and Huang, B. (2014). Mechanism of salinity tolerance in plants: physiological, biochemical, and molecular characterization. Int. J. Genom. 2014:18. doi: 10.1155/2014/701596

Gupta, N., Thind, S. K., and Bains, N. S. (2014). Glycine betaine application modifies biochemical attributes of osmotic adjustment in drought stressed wheat. Plant Growth Regul. 72, 221-228. doi: 10.1007/s10725-013-9853-0

Hattori, T., Mitsuya, S., Fujiwara, T., Jagendorf, A. T., and Takabe, T. (2009). Tissue specificity of glycinebetaine synthesis in barley. Plant Sci. 176, 112-118. doi: $10.1016 /$ j.plantsci.2008.10.003

Hayashi, H., Alia, Mustardy, L., Deshnium, P., Ida, M., and Murata, N. (1997). Transformation of Arabidopsis thaliana with the codA gene for choline oxidase; accumulation of glycinebetaine and enhanced tolerance to salt and cold stress. Plant J. 12, 133-142. doi: 10.1046/j.1365-313X.1997.12010133.x

Hayashi, H., Alia, Sakamoto, A., Nonaka, H., Chen, T. H. H., and Murata, N. (1998). Enhanced germination under high-salt conditions of seeds of transgenic Arabidopsis with a bacterial gene (codA) for choline oxidase. J. Plant Res. 111:357. doi: 10.1007/bf02512197

Holmström, K. O., Somersalo, S., Mandal, A., Palva, T. E., and Welin, B. (2000). Improved tolerance to salinity and low temperature in transgenic tobacco producing glycine betaine. J. Exp. Bot. 51, 177-185. doi: 10.1093/jexbot/51.343.177

Hu, L., Hu, T., Zhang, X., Pang, H., and Fu, J. (2012). Exogenous glycine betaine ameliorates the adverse effect of salt stress on perennial ryegrass. J. Am. Soc. Hortic. Sci. 137, 38-46. doi: 10.21273/JASHS.137.1.38

Huang, J., Hirji, R., Adam, L., Rozwadowski, K. L., Hammerlindl, J. K., Keller, W. A., et al. (2000). Genetic engineering of glycinebetaine production toward enhancing stress tolerance in plants: metabolic limitations. Plant Physiol. 122, 747-756. doi: 10.1104/pp.122.3.747

Igamberdiev, A. U., and Kleczkowski, L. A. (2018). The glycerate and phosphorylated pathways of serine synthesis in plants: the branches of plant glycolysis linking carbon and nitrogen metabolism. Front. Plant Sci. 9:318. doi: $10.3389 /$ fpls.2018.00318

Ikuta, S., Imamura, S., Misaki, H., and Horiuti, Y. (1977). Purification and characterization of Choline oxidase from Arthrobacter globiformis. J. Biochem. 82, 1741-1749. doi: 10.1093/oxfordjournals.jbchem.a131872

Islam, M. M., Hoque, A., Okuma, E., Nasrin, M., Banu, A., Shimoishi, Y., et al. (2009). Exogenous proline and glycinebetaine increase antioxidant enzyme activities and confer tolerance to cadmium stress in cultured tobacco cells. J. Plant Physiol. 166, 1587-1597. doi: 10.1016/j.jplph.2009.04.002

Jokinen, K., Somersalo, S., Mäkelä, P., Urbano, P., Rojo, C., González, J. M. A., et al. (1999). Glycinebetaine from sugar beet enhances the yield of field-grown tomatoes. Acta Hortic. 487, 233-236. doi: 10.17660/ActaHortic.1999.487.33

Kathuria, H., Giri, J., Nataraja, K. N., Murata, N., Udayakumar, M., and Tyagi, A. K. (2009). Glycinebetaine-induced water-stress tolerance in codA-expressing transgenic indica rice is associated with up-regulation of several stress responsive genes. Plant Biotechnol. J. 7, 512-526. doi: 10.1111/j.1467-7652.2009. 00420.x

Khan, M., Yu, X., Kikuchi, A., Asahina, M., and Watanabe, K. (2009). Genetic engineering of Glycine betaine biosynthesis to enhance abiotic stress tolerance in plants. Plant Biotechnol. 26, 125-134. doi: 10.5511/plantbiotechnology.26.125

Khan, M. I. R., Asgher, M., and Khan, N. A. (2014). Alleviation of salt-induced photosynthesis and growth inhibition by salicylic acid involves glycinebetaine and ethylene in mungbean (Vigna radiata L.). Plant Physiol. Biochem. 80, 67-74. doi: 10.1016/j.plaphy.2014.03.026

Khan, M. I. R., Iqbal, N., Masood, A., and Khan, N. A. (2012). Variation in salt tolerance of wheat cultivars: role of glycinebetaine and ethylene. Pedosphere 22, 746-754. doi: 10.1016/S1002-0160(12)60060-5

Khan, S. H., Ahmad, N., Ahmad, F., and Kumar, R. (2010). Naturally occurring organic osmolytes: from cell physiology to disease prevention. IUBMB Life 62, 891-895. doi: 10.1002/iub.406

Kishitani, S., Takanami, T., Suzuki, M., Oikawa, M., Yokoi, S., Ishitani, M. et al. (2000). Compatibility of glycinebetaine in rice plants: evaluation using transgenic rice plants with a gene for peroxisomal betaine aldehyde dehydrogenase from barley. Plant Cell Environ. 23, 107-114. doi: 10.1046/j. 1365-3040.2000.00527.x

Kishitani, S., Watanabe, K., Yasuda, S., Arakawa, K., and Takabe, T. (1994). Accumulation of glycinebetaine during cold acclimation and freezing tolerance in leaves of winter and spring barley plants. Plant Cell Environ. 17, 89-95. doi: 10.1111/j.1365-3040.1994.tb00269.x

Kleczkowski, L. A., and Givan, C. V. (1988). Serine formation in leaves by mechanisms other than the glycolate pathway. J. Plant Physiol. 132, 641-652. doi: 10.1016/S0176-1617(88)80223-2

Kumar, S., Dhingra, A., and Daniell, H. (2004). Plastid-expressed betaine aldehyde dehydrogenase gene in carrot cultured cells, roots, and leaves confers enhanced salt tolerance. Plant Physiol. 136, 2843-2854. doi: 10.1104/pp.104.045187

Kumar, V., Shriram, V., Hoque, T., Hasan, M., Burritt, D., and Hossain, M. A. (2017). "Glycinebetaine-mediated abiotic oxidative-stress tolerance in plants: physiological and biochemical mechanisms," in Stress Signaling in Plants: Genomics and Proteomics Perspective, eds M. Sarwat, A. Ahmad, M. Z. Abdin, and M. M. Ibrahim (Cham: Springer), 111-133.

Kurepin, L. V., Ivanov, A. G., Zaman, M., Pharis, R. P., Allakhverdiev, S. I., Hurry, V., et al. (2015). Stress-related hormones and glycinebetaine interplay in protection of photosynthesis under abiotic stress conditions. Photosynth. Res. 126, 221-235. doi: 10.1007/s11120-015-0125-X

Kwon, Y., Yu, S.-I., Lee, H., Yim, J. H., Zhu, J.-K., and Lee, B.-H. (2012). Arabidopsis serine decarboxylase mutants implicate the roles of ethanolamine in plant growth and development. Int. J. Mol. Sci. 13, 3176-3188. doi: 10.3390/ ijms 13033176

Ladyman, J. A. R., Hitz, W. D., and Hanson, A. D. (1980). Translocation and metabolism of glycine betaine by barley plants in relation to water stress. Planta 150, 191-196. doi: 10.1007/bf00390825

Li, D., Zhang, T., Wang, M., Liu, Y., Brestic, M., Chen, T. H. H., et al. (2019). Genetic engineering of the biosynthesis of glycine betaine modulates phosphate homeostasis by regulating phosphate acquisition in tomato. Front. Plant Sci. 9:1995. doi: 10.3389/fpls.2018.01995

Liu, Z.-H., Zhang, H.-M., Li, G.-L., Guo, X.-L., Chen, S.-Y., Liu, G.-B., et al. (2011). Enhancement of salt tolerance in alfalfa transformed with the gene encoding for betaine aldehyde dehydrogenase. Euphytica 178, 363-372. doi: 10.1007/s10681010-0316-7

Lv, S., Yang, A., Zhang, K., Wang, L., and Zhang, J. (2007). Increase of glycinebetaine synthesis improves drought tolerance in cotton. Mol. Breed. 20, 233-248. doi: 10.1007/s11032-007-9086-X

Ma, Q.-Q., Wang, W., Li, Y.-H., Li, D.-Q., and Zou, Q. (2006). Alleviation of photoinhibition in drought-stressed wheat (Triticum aestivum) by foliarapplied glycinebetaine. J. Plant Physiol. 163, 165-175. doi: 10.1016/j.jplph.2005. 04.023

Ma, X. L., Wang, Y. J., Xie, S. L., Li, F., and Wang, W. (2006). Glycine betaine applied through roots protects the photosynthetic apparatus of tobacco seedlings under water stress. J. Plant Physiol. Mol. Biol. 32, 465-472.

Ma, X. L., Wang, Y. J., Xie, S. I., Wang, C., and Wang, W. (2007). Glycinebetaine application ameliorates negative effects ofdrought stress in tobacco. Russ. J. Plant Physiol. 54, 472-479. doi: 10.1134/S1021443707 040061 
Maas, E. V., and Poss, J. A. (1989). Salt sensitivity of wheat at various growth stages. Irrigat. Sci. 10, 29-40. doi: 10.1007/BF00266155

Mäkelä, P., Kontturi, M., Pehu, E., and Somersalo, S. (1999). Photosynthetic response of drought- and salt-stressed tomato and turnip rape plants to foliarapplied glycinebetaine. Physiol. Plant. 105, 45-50. doi: 10.1034/j.1399-3054. 1999.105108.x

Mäkelä, P., Mantila, J., Hinkkanen, R., Pehu, E., and Peltonen-Sainio, P. (1996). Effect of foliar applications of glycinebetaine on stress tolerance, growth, and yield of spring cereals and summer turnip rape in finland. J. Agron. Crop Sci. 176, 223-234. doi: 10.1111/j.1439-037X.1996.tb00467.x

Mäkelä, P., Munns, R., Colmer, T., Condon, A. G., and Peltonen-Sainio, P. (1998). Effect of foliar applications of glycinebetaine on stomatal conductance, abscisic acid and solute concentrations in leaves of salt- or drought-stressed tomato. Funct. Plant Biol. 25, 655-663. doi: 10.1071/PP98024

Malekzadeh, P. (2015). Influence of exogenous application of glycinebetaine on antioxidative system and growth of salt-stressed soybean seedlings (Glycine max L.). Physiol. Mol. Biol. Plants 21, 225-232. doi: 10.1007/s12298-015-0292-4

Manaf, H. H. (2016). Beneficial effects of exogenous selenium, glycine betaine and seaweed extract on salt stressed cowpea plant. Ann. Agric. Sci. 61, 41-48. doi: 10.1016/j.aoas.2016.04.003

Masood, A., Per, T., Asgher, D. M., Mehar, F., Iqbal, M., Khan, R., et al. (2016). "Glycine betaine: role in shifting plants toward adaptation under extreme environments," in Osmolytes and Plants Acclimation to Changing Environment: Emerging Omics Technologies, eds N. Iqbal, R. A. Nazar, and N. Khan (Berlin: Springer).

McCue, K. F., and Hanson, A. D. (1990). Drought and salt tolerance: towards understanding and application. Trends Biotechnol. 8, 358-362. doi: 10.1016/ 0167-7799(90)90225-M

McNeil, S. D., Nuccio, M. L., Ziemak, M. J., and Hanson, A. D. (2001). Enhanced synthesis of choline and glycine betaine in transgenic tobacco plants that overexpress phosphoethanolamine $\mathrm{N}$-methyltransferase. Proc. Natl. Acad. Sci. U.S.A. 98, 10001-10005. doi: 10.1073/pnas.171228998

McNeil, S. D., Rhodes, D., Russell, B. L., Nuccio, M. L., Shachar-Hill, Y., and Hanson, A. D. (2000). Metabolic modeling identifies key constraints on an engineered glycine betaine synthesis pathway in Tobacco. Plant Physiol. 124, 153-162. doi: 10.1104/pp.124.1.153

Meloni, D. A., Gulotta, M. R., Martínez, C. A., and Oliva, M. A. (2004). The effects of salt stress on growth, nitrate reduction and proline and glycinebetaine accumulation in Prosopis alba. Braz. J. Plant Physiol. 16, 39-46. doi: 10.1590/ S1677-04202004000100006

Mitsuya, S., Kozaki, K., and Takabe, T. (2013). Tissue localization of the glycine betaine biosynthetic enzymes in barley leaves. Plant Product. Sci. 16, 117-122. doi: $10.1626 /$ pps. 16.117

Mohanty, A., Kathuria, H., Ferjani, A., Sakamoto, A., Mohanty, P., Murata, N., et al. (2002). Transgenics of an elite indica rice variety Pusa Basmati 1 harbouring the codA gene are highly tolerant to salt stress. Theor. Appl. Genet. 106, 51-57. doi: $10.1007 / \mathrm{s} 00122-002-1063-5$

Munns, R., and Tester, M. (2008). Mechanisms of salinity tolerance. Annu. Rev. Plant Biol. 59, 651-681. doi: 10.1146/annurev.arplant.59.032607.092911

Nakamura, T., Ishitani, M., Harinasut, P., Nomura, M., Takabe, T., and Takabe, T. (1996). Distribution of glycinebetaine in old and young leaf blades of salt-stressed barley plants. Plant Cell Physiol. 37, 873-877. doi: 10.1093/ oxfordjournals.pcp.a029026

Nuccio, M. L., McNeil, S. D., Ziemak, M. J., Hanson, A. D., Jain, R. K., and Selvaraj, G. (2000). Choline import into chloroplasts limits glycine betaine synthesis in tobacco: analysis of plants engineered with a chloroplastic or a cytosolic pathway. Metab. Eng. 2, 300-311. doi: 10.1006/mben.2000. 0158

Nuccio, M. L., Russell, B. L., Nolte, K. D., Rathinasabapathi, B., Gage, D. A., and Hanson, A. D. (1998). The endogenous choline supply limits glycine betaine synthesis in transgenic tobacco expressing choline monooxygenase. Plant J. 16, 487-496. doi: 10.1046/j.1365-313x.1998.00316.x

Osman, H. S. (2015). Enhancing antioxidant-yield relationship of pea plant under drought at different growth stages by exogenously applied glycine betaine and proline. Ann. Agric. Sci. 60, 389-402. doi: 10.1016/j.aoas.2015.10.004

Osman, H. S., and Salim, B. B. M. (2016). Influence of exogenous application of some phytoprotectants on growth, yield and pod quality of snap bean under $\mathrm{NaCl}$ salinity. Ann. Agric. Sci. 61, 1-13. doi: 10.1016/j.aoas.2016.05.001
Oukarroum, A., El Madidi, S., and Strasser, R. J. (2012). Exogenous glycine betaine and proline play a protective role in heat-stressed barley leaves (Hordeum vulgare L.): a chlorophyll a fluorescence study. Plant Biosyst. 146, 1037-1043. doi: 10.1080/11263504.2012.697493

Papageorgiou, G. C., Fujimura, Y., and Murata, N. (1991). Protection of the oxygen-evolving photosystem II complex by glycinebetaine. Biochim. Biophys. Acta (BBA) - Bioenerget. 1057, 361-366. doi: 10.1016/S0005-2728(05)80148-3

Park, E.-J., Jeknic, Z., and Chen, T. H. H. (2006). Exogenous application of glycinebetaine increases chilling tolerance in tomato plants. Plant Cell Physiol. 47, 706-714. doi: 10.1093/pcp/pcj041

Park, E.-J., Jeknić, Z., Pino, M.-T., Murata, N., and Chen, T. H.-H. (2007). Glycinebetaine accumulation is more effective in chloroplasts than in the cytosol for protecting transgenic tomato plants against abiotic stress. Plant Cell Environ. 30, 994-1005. doi: 10.1111/j.1365-3040.2007.01694.x

Prasad, K. V. S. K., Sharmila, P., Kumar, P. A., and Saradhi, P. P. (2000). Transformation of Brassica juncea (L.) Czern with bacterial codA gene enhances its tolerance to salt stress. Mol. Breed. 6, 489-499. doi: 10.1023/a:1026542109965

Quan, R., Shang, M., Zhang, H., Zhao, Y., and Zhang, J. (2004). Improved chilling tolerance by transformation with betA gene for the enhancement of glycinebetaine synthesis in maize. Plant Sci. 166, 141-149. doi: 10.1016/j. plantsci.2003.08.018

Rajasekaran, L., Kriedemann, P., Aspinall, D., and Paleg, L. G. (1997). Physiological significance of proline and glycinebetaine: maintaining photosynthesis during $\mathrm{NaCl}$ stress in wheat. Photosynthetica 34, 357-366. doi: 10.1023/A: 1006855816437

Rathinasabapathi, B., Burnet, M., Russell, B. L., Gage, D. A., Liao, P.-C., Nye, G. J., et al. (1997). Choline monooxygenase, an unusual iron-sulfur enzyme catalyzing the first step of glycine betaine synthesis in plants: prosthetic group characterization and cDNA?cloning. Proc. Natl. Acad. Sci. U.S.A. 94, 3454-3458. doi: 10.1073/pnas.94.7.3454

Raza, M. A., Saleem, M. F., Shah, G., Khan, I. H., and Raza, A. (2014). Exogenous application of glycinebetaine and potassium for improving water relations and grain yield of wheat under drought. J. Soil Sci. Plant Nutr. 14, 348-364. doi: $10.4067 /$ S0718-95162014005000028

Raza, S. H., Athar, H. R., Ashraf, M., and Hameed, A. (2007). Glycinebetaineinduced modulation of antioxidant enzymes activities and ion accumulation in two wheat cultivars differing in salt tolerance. Environ. Exp. Bot. 60, 368-376. doi: 10.1016/j.envexpbot.2006.12.009

Reddy, K., Henry, W. B., Seepaul, R., Lokhande, S., Gajanayake, B., and Brand, D. (2013). Exogenous application of glycinebetaine facilitates maize (Zea mays L.) growth under water deficit conditions. Am. J. Exp. Agric. 3, 1-13. doi: 10.9734/AJEA/2013/1730

Rentsch, D., Hirner, B., Schmelzer, E., and Frommer, W. B. (1996). Salt stressinduced proline transporters and salt stress-repressed broad specificity amino acid permeases identified by suppression of a yeast amino acid permeasetargeting mutant. Plant Cell 8, 1437-1446. doi: 10.1105/tpc.8.8.1437

Rhodes, D., and Hanson, A. (1993). Quaternary ammonium and tertiary sulfonium compounds in higher plants. Annu. Rev. Plant Physiol. Plant Mol. Biol. 44, 357-384. doi: 10.1146/annurev.pp.44.060193.002041

Rhodes, D., Nadolska-Orczyk, A., and Rich, P. J. (2002). "Salinity, Osmolytes and compatible solutes," in Salinity: Environment - Plants - Molecules, eds A. Läuchli and U. Lüttge (Dordrecht: Springer), 181-204.

Rhodes, D., Rich, P. J., Brunk, D. G., Ju, G. C., Rhodes, J. C., Pauly, M. H., et al. (1989). Development of two isogenic sweet corn hybrids differing for glycinebetaine content. Plant Physiol. 91, 1112-1121. doi: 10.1104/pp.91.3.1112

Robinson, S., and Jones, G. (1986). Accumulation of glycinebetaine in chloroplasts provides osmotic adjustment during salt stress. Funct. Plant Biol. 13, 659-668. doi: 10.1071/PP9860659

Rontein, D., Nishida, I., Tashiro, G., Yoshioka, K., Wu, W.-I., Voelker, D. R., et al. (2001). Plants synthesize ethanolamine by direct decarboxylation of serine using a pyridoxal phosphate enzyme. J. Biol. Chem. 276, 35523-35529. doi: 10.1074/jbc.M106038200

Rozwadowski, K. L., Khachatourians, G. G., and Selvaraj, G. (1991). Choline oxidase, a catabolic enzyme in Arthrobacter pascens, facilitates adaptation to osmotic stress in Escherichia coli. J. Bacteriol. 173, 472-478. doi: 10.1128/jb.173. 2.472-478.1991

Sairam, R. K., Rao, K. V., and Srivastava, G. C. (2002). Differential response of wheat genotypes to long term salinity stress in relation to oxidative stress, 
antioxidant activity and osmolyte concentration. Plant Sci. 163, 1037-1046. doi: 10.1016/S0168-9452(02)00278-9

Sakamoto, A., and Murata, A. N. (1998). Metabolic engineering of rice leading to biosynthesis of glycinebetaine and tolerance to salt and cold. Plant Mol. Biol. 1998, 1011-1019. doi: 10.1023/A:1006095015717

Sakamoto, A., and Murata, N. (2000). Genetic engineering of glycinebetaine synthesis in plants: current status and implications for enhancement of stress tolerance. J. Exp. Bot. 51, 81-88. doi: 10.1093/jexbot/51.342.81

Sakamoto, A., and Murata, N. (2002). The role of glycine betaine in the protection of plants from stress: clues from transgenic plants. Plant Cell Environ. 25, 163-171. doi: 10.1046/j.0016-8025.2001.00790.x

Salvi, F., Wang, Y.-F., Weber, I. T., and Gadda, G. (2014). Structure of choline oxidase in complex with the reaction product glycine betaine. Acta Crystallograph. Sect. D 70, 405-413. doi: 10.1107/S1399004713029283

Saneoka, H., Nagasaka, C., Hahn, D. T., Yang, W. J., Premachandra, G. S., Joly, R. J., et al. (1995). Salt tolerance of glycinebetaine-deficient and -containing maize lines. Plant Physiol. 107, 631-638. doi: 10.1104/pp.107.2.631

Schwacke, R., Grallath, S., Breitkreuz, K. E., Stransky, E., Stransky, H., Frommer, W. B., et al. (1999). LeProT1, a transporter for proline, glycine betaine, and $\gamma$-amino butyric acid in tomato pollen. Plant Cell 11, 377-391. doi: 10.1105/ tpc.11.3.377

Shan, T., Jin, P., Zhang, Y., Huang, Y., Wang, X., and Zheng, Y. (2016). Exogenous glycine betaine treatment enhances chilling tolerance of peach fruit during cold storage. Postharv. Biol. Technol. 114, 104-110. doi: 10.1016/j.postharvbio.2015. 12.005

Sharma, S. S., and Dietz, K. J. (2006). The significance of amino acids and amino acid-derived molecules in plant responses and adaptation to heavy metal stress. J. Exp. Bot. 57, 711-726. doi: 10.1093/jxb/erj073

Shimomura, T., Itoh, T., Sumiya, T., Mizukami, F., and Ono, M. (2009). Amperometric determination of choline with enzyme immobilized in a hybrid mesoporous membrane. Talanta 78, 217-220. doi: 10.1016/j.talanta.2008.11.008

Storey, R., Ahmad, N., and Wyn Jones, R. G. (1977). Taxonomic and ecological aspects of the distribution of glycinebetaine and related compounds in plants. Oecologia 27, 319-332. doi: 10.1007/BF00345565

Subbarao, G. V., Wheeler, R. M., Levine, L. H., and Stutte, G. W. (2001). Glycine betaine accumulation, ionic and water relations of red-beet at contrasting levels of sodium supply. J. Plant Physiol. 158, 767-776. doi: 10.1078/0176-1617-00309

Sulpice, R., Gibon, Y., Bouchereau, A., and Larher, F. (1998). Exogenously supplied glycine betaine in spinach and rapeseed leaf discs: compatibility or noncompatibility? Plant Cell Environ. 21, 1285-1292. doi: 10.1046/j.1365-3040. 1998.00362.x

Sulpice, R., Tsukaya, H., Nonaka, H., Mustardy, L., Chen, T. H. H., and Murata, N. (2003). Enhanced formation of flowers in salt-stressed Arabidopsis after genetic engineering of the synthesis of glycine betaine. Plant J. 36, 165-176. doi: 10. 1046/j.1365-313X.2003.01873.x

Takabe, T., Nakamura, T., Nomura, M., Hayashi, Y., Ishitani, M., Muramoto, Y., et al. (1998). "8 - Glycinebetaine and the genetic engineering of salinity tolerance in plants," in Stress Responses of Photosynthetic Organisms, eds K. Satoh and N. Murata (Amsterdam: Elsevier), 115-131. doi: 10.1016/B978-0444-82884-2.50011-X

Tsutsumi, K., Yamada, N., Cha-um, S., Tanaka, Y., and Takabe, T. (2015). Differential accumulation of glycinebetaine and choline monooxygenase in bladder hairs and lamina leaves of Atriplex gmelini under high salinity. J. Plant Physiol. 176, 101-107. doi: 10.1016/j.jplph.2014.12.009

Waditee, R., Hibino, T., Tanaka, Y., Nakamura, T., Incharoensakdi, A., Hayakawa, S., et al. (2002). Functional characterization of betaine/proline transporters in betaine-accumulating mangrove. J. Biol. Chem. 277, 18373-18382. doi: 10.1074/jbc.M112012200

Wang, Q.-B., Xu, W., Xue, Q.-Z., and Su, W.-A. (2010). Transgenic Brassica chinensis plants expressing a bacterial codA gene exhibit enhanced tolerance to extreme temperature and high salinity. J. Zhejiang Univers. Sci. B 11, 851-861. doi: $10.1631 /$ jzus.B1000137

Wang, Y., and Nii, N. (2000). Changes in chlorophyll, ribulose bisphosphate carboxylase-oxygenase, glycine betaine content, photosynthesis and transpiration in Amaranthus tricolor leaves during salt stress. J. Hortic. Sci. Biotechnol. 75, 623-627. doi: 10.1080/14620316.2000.11511297

Wani, S. H., Singh, N. B., Haribhushan, A., and Mir, J. I. (2013). Compatible solute engineering in plants for abiotic stress tolerance - Role of glycine betaine. Curr. Genom. 14, 157-165. doi: 10.2174/138920291131403 0001

Wei, D., Zhang, W., Wang, C., Meng, Q., Li, G., Chen, T. H. H., et al. (2017). Genetic engineering of the biosynthesis of glycinebetaine leads to alleviate saltinduced potassium efflux and enhances salt tolerance in tomato plants. Plant Sci. 257, 74-83. doi: 10.1016/j.plantsci.2017.01.012

Weigel, P., Weretilnyk, E. A., and Hanson, A. D. (1986). Betaine aldehyde oxidation by spinach chloroplasts. Plant Physiol. 82, 753-759. doi: 10.1104/pp.82.3.753

Weretilnyk, E. A., Bednarek, S., McCue, K. F., Rhodes, D., and Hanson, A. D. (1989). Comparative biochemical and immunological studies of the glycine betaine synthesis pathway in diverse families of dicotyledons. Planta 178, 342-352. doi: $10.1007 /$ bf00391862

Weretilnyk, E. A., and Hanson, A. D. (1990). Molecular cloning of a plant betainealdehyde dehydrogenase, an enzyme implicated in adaptation to salinity and drought. Proc. Natl. Acad. Sci. U.S.A. 87, 2745-2749. doi: 10.1073/pnas.87.7. 2745

Wingler, A., Lea, P. J., Quick, W. P., and Leegood, R. C. (2000). Photorespiration: metabolic pathways and their role in stress protection. Philos. Trans. R. Soc. Lon. Ser. B Biol. Sci. 355, 1517-1529.

Woodrow, P., Ciarmiello, L. F., Annunziata, M. G., Pacifico, S., Iannuzzi, F., Mirto, A., et al. (2017). Durum wheat seedling responses to simultaneous high light and salinity involve a fine reconfiguration of amino acids and carbohydrate metabolism. Physiol. Plant. 159, 290-312. doi: 10.1111/ppl.12513

Xu, Z., Sun, M., Jiang, X., Sun, H., Dang, X., Cong, H., et al. (2018). Glycinebetaine biosynthesis in response to osmotic stress depends on jasmonate signaling in watermelon suspension cells. Front. Plant Sci. 9:1469. doi: 10.3389/fpls.2018. 01469

Yamada, N., Promden, W., Yamane, K., Tamagake, H., Hibino, T., Tanaka, Y., et al. (2009). Preferential accumulation of betaine uncoupled to choline monooxygenase in young leaves of sugar beet - Importance of long-distance translocation of betaine under normal and salt-stressed conditions. J. Plant Physiol. Mol. Biol. 166, 2058-1070. doi: 10.1016/j.jplph.2009.06.016

Yamada, N., Sakakibara, S., Tsutsumi, K., Waditee, R., Tanaka, Y., and Takabe, T. (2011). Expression and substrate specificity of betaine/proline transporters suggest a novel choline transport mechanism in sugar beet. J. Plant Physiol. 168, 1609-1616. doi: 10.1016/j.jplph.2011.03.007

Yang, X. H., Wen, X. G., Gong, H. M., Lu, Q. T., Yang, Z. P., Tang, Y. L., et al. (2007). Genetic engineering of the biosynthesis of glycinebetaine enhances thermotolerance of photosystem II in tobacco plants. Planta 225, 719-733. doi: 10.1007/s00425-006-0380-3

Yao, T., Shaharuddin, A., Chai, H., Mahmood, M., Shaharuddin, N., Chai Ling, H., et al. (2016). Application of glycine betaine alleviates salt induced damages more efficiently than ascorbic acid in in vitro rice shoots. Austr. J. Basic Appl. Sci. 10, $58-65$.

Yu, X., Kikuchi, A., Matsunaga, E., Morishita, Y., Nanto, K., Sakurai, N., et al. (2009). Establishment of the evaluation system of salt tolerance on transgenic woody plants in the special netted-house. Plant Biotechnol. 26, 135-141. doi: 10.5511/plantbiotechnology.26.135

Zhang, X. Y., Liang, C., Wang, G. P., Luo, Y., and Wang, W. (2010). The protection of wheat plasma membrane under cold stress by glycine betaine overproduction. Biol. Plant. 54, 83-88. doi: 10.1007/s10535-010-0012-4

Zhao, X.-X., Ma, Q.-Q., Liang, C., Fang, Y., Wang, Y.-Q., and Wang, W. (2007). Effect of glycinebetaine on function of thylakoid membranes in wheat flag leaves under drought stress. Biol. Plant. 51, 584-588. doi: 10.1007/s10535-007-0128-3

Zhao, Y., Aspinall, D., and Paleg, L. G. (1992). Protection of membrane integrity in Medicago sativa L. by glycinebetaine against the effects of freezing. J. Plant Physiol. 140, 541-543. doi: 10.1016/S0176-1617(11)80785-6

Conflict of Interest Statement: The authors declare that the research was conducted in the absence of any commercial or financial relationships that could be construed as a potential conflict of interest.

Copyright (๔ 2019 Annunziata, Ciarmiello, Woodrow, Dell'Aversana and Carillo. This is an open-access article distributed under the terms of the Creative Commons Attribution License (CC BY). The use, distribution or reproduction in other forums is permitted, provided the original author(s) and the copyright owner(s) are credited and that the original publication in this journal is cited, in accordance with accepted academic practice. No use, distribution or reproduction is permitted which does not comply with these terms. 